\title{
Historia, Estado y nación. El constitucionalismo y los procesos de descolonización*
}

Artículos

\section{History, State and Nation. Constitutionalism and decolonization processes}

\author{
Michael Riegner \\ Universidad Humboldt de Berlin, Alemania \\ ORCID: https://orcid.org/0000-0003-4777-6896 \\ Daniel Bonilla Maldonado ${ }^{\text {a }}$ \\ Universidad de los Andes, Colombia \\ dbonilla@uniandes.edu.co \\ ORCID: https://orcid.org/0000-0002-8303-6783
}

DOI: https://doi.org/10.11144/Javeriana.vj70.henc

Recibido: 04 Septiembre 2020

Aceptado: 23 Febrero 2021

Publicado: 22 Octubre 2021

\section{Resumen:}

El objetivo de este artículo es describir y analizar los patrones y elementos constitucionales que estructuran los procesos de descolonización. Más precisamente, el artículo presenta los siguientes cuatro argumentos. Primero, los patrones discursivos y prácticos estructurales que atraviesan los procesos constitucionales descoloniales giran en torno a las siguientes categorías: tiempo (historia), espacio (Estado) y sujeto (nación). Segundo, las comunidades políticas poscoloniales típicamente articulan la relación entre identidad, historia y constitución, haciendo uso de tres movimientos discursivos: mímesis, poiesis e hibridación. Las nuevas subjetividades colectivas e individuales que emergen en las sociedades poscoloniales se construyen, en parte, jurídicamente. Las constituciones poscoloniales contribuyen a construir estas identidades mediante las decisiones que toman sobre cómo ha de incorporarse e interpretarse el pasado político-jurídico imperial en el presente y el futuro de la nueva comunidad política. Tercero, la forma espacial que toma la nueva sociedad poscolonial es la del Estado independiente y soberano. Los fundadores de las sociedades poscoloniales disponían de modelos espaciales jurídicos y políticos alternativos para organizar espacialmente sus sociedades, entre otros, las federaciones de pueblos o Estados. No obstante, reprodujeron las premisas sustanciales y los patrones prácticos que constituyen la columna vertebral del modelo articulado paradigmáticamente en el Pacto de Westphalia. Finalmente, cuarto, la nación es el sujeto colectivo transtemporal que ocupa las coordenadas espaciales y temporales que estructuran a las nuevas sociedades poscoloniales. La gramática del constitucionalismo moderno, por tanto, potencia y al mismo tiempo limita la imaginación de los fundadores de las comunidades políticas poscoloniales.

Palabras clave: descolonización y constitucionalismo, nación poscolonial, Estado poscolonial, historia e identidad poscolonial.

\begin{abstract}
:
This article aims to describe and analyze the constitutional patterns and elements that structure decolonization processes. More specifically, the article presents the following four arguments. First, the structural discursive and practical patterns that cut across decolonial constitutional processes revolve around the following categories: time (history), space (state), and subject (nation). Second, postcolonial political communities articulate the relationship between identity, history, and Constitution using three discursive movements: mimesis, poiesis, and hybridization. The new collective and individual subjectivities that emerge in postcolonial societies are constructed, in part, legally. Postcolonial Constitutions contribute to building these identities through the decisions they make about how to incorporate and interpret the imperial political and legal past in the present and the future of the new political community. Third, the spatial form that the new postcolonial society takes is that of the independent and sovereign State. The founders of postcolonial societies had alternative legal and political spatial models to spatially organize their societies, among others, the federations of peoples or states. However, they reproduced the substantial premises and practical patterns that constitute the backbone of the model articulated paradigmatically in the Pact of Westphalia. Finally, fourth, the nation is the transtemporal collective subject that occupies the spatial and temporal coordinates that structure the new postcolonial societies. The grammar of modern constitutionalism, therefore, empowers and at the same time limits the imagination of the founders of postcolonial political communities.
\end{abstract}

Keywords: decolonization and constitutionalism, postcolonial nation, postcolonial state, history and postcolonial identity.

Notas de autor

${ }^{a}$ Autor de correspondencia. Correo electrónico: dbonilla@uniandes.edu.co 


\section{Introducción}

La descolonización es el proceso por medio del cual los imperios europeos colapsan y las antiguas colonias crean nuevos Estados independientes en la modernidad clásica y tardía ${ }^{1}$. Desde el punto de vista jurídico, en las colonias, estos procesos típicamente terminan con la expedición de una nueva constitución. Estas constituciones simbolizan y materializan el carácter soberano e independiente de las nuevas comunidades políticas. Asimismo, estas constituciones sintetizan los objetivos políticos que persiguen, las estructuras institucionales que permiten alcanzarlos y las formas de distribuir y controlar el poder que dan forma a estas colectividades. Descolonización y constitución, por tanto, son categorías y prácticas que se entrecruzan. Ahora bien, la descolonización es un proceso que también está atravesado por la violencia ${ }^{2}$. La independencia está cruzada por procesos militares, económicos y político-jurídicos violentos, entre otros, las guerras de independencia, la asimilación cultural y la aceptación, rechazo o transformación de las tradiciones jurídicas impuestas por el imperio. Estas rupturas violentas no necesariamente acabaron con las estructuras e ideas coloniales. En el campo del derecho, algunas instituciones y prácticas murieron, otras mutaron y algunas más persistieron luego de que las colonias se independizaran formalmente.

Desde una perspectiva teórica, la descolonización también se relaciona con una corriente de pensamiento crítico, la teoría poscolonial o decolonial ${ }^{3}$. Esta perspectiva crítica no solo reflexiona sobre las características y consecuencias que tienen los procesos de descolonización en las colonias, sino que también llama la atención sobre los legados y repercusiones que ha tenido la descolonización en las metrópolis europeas, cuestiones que usualmente son ignoradas por la literatura jurídica ${ }^{4}$.

El objetivo del texto es describir y analizar los patrones y elementos jurídicos estructurales que atraviesen los procesos de descolonización. La descripción y análisis de estos procesos se organizan alrededor de las siguientes cuatro tesis. Primera, los patrones discursivos y prácticos estructurales que atraviesan los procesos constitucionales descoloniales giran en torno a las siguientes tres categorías: tiempo (historia), espacio (Estado) y sujeto (nación). Segunda, la primera categoría determina las formas como en cada comunidad política postcolonial se articula la relación entre identidad, historia y constitución. Las nuevas subjetividades colectivas e individuales que emergen en las sociedades poscoloniales se construyen, en parte, jurídicamente. Las constituciones poscoloniales contribuyen a construir estas identidades mediante las decisiones que toman sobre cómo ha de interpretarse e incorporarse el pasado político-jurídico imperial en el presente y el futuro de la nueva comunidad política. Estas decisiones sobre la historia imperial y poscolonial, argumentamos, se pueden describir y comprender haciendo uso de los conceptos de mímesis, poiesis e hibridación.

Tercera, la segunda categoría concreta la forma espacial que toma la nueva sociedad poscolonial: el Estado independiente y soberano. Los fundadores de las sociedades poscoloniales disponían de esquemas espaciales jurídicos y políticos alternativos para organizar espacialmente sus sociedades, entre otros, las federaciones de pueblos o Estados. No obstante, reprodujeron las premisas sustanciales y los patrones prácticos que constituyen la columna vertebral del modelo articulado paradigmáticamente en el Pacto de Westphalia. Finalmente, la nación es el sujeto colectivo transtemporal que ocupa las coordenadas espaciales y temporales que estructuran a las nuevas sociedades poscoloniales. La gramática del constitucionalismo moderno, por tanto, potencia y al mismo tiempo limita la imaginación de los fundadores de las comunidades políticas poscoloniales. Las decisiones constitucionales que toman las sociedades poscoloniales con respecto a las maneras como las nociones de tiempo, espacio y sujeto, que las materializan históricamente, han de configurarse, se construyen y, al mismo tiempo, entran en tensión con las reglas y principios que controlan los usos del vocabulario del constitucionalismo moderno.

Las experiencias constitucionales que fundamentan estas cuatro tesis son tomadas de órdenes jurídicos de distintas regiones del mundo. No obstante, dada la complejidad del tema, este artículo no puede hacer justicia a la riqueza temática y variaciones regionales de la descolonización. En consecuencia, los ejemplos que se 
presentan en el artículo apuntan a cubrir los casos típicos y atípicos de descolonización, aunque la selección de casos esté limitada por el hecho de que los estudios constitucionales existentes sobre la descolonización han estado centrados en pocos casos, especialmente, en las excolonias británicas como India.

Para alcanzar el objetivo mencionado y fundamentar las cuatro tesis que constituyen la columna vertebral del escrito, el artículo se divide en tres partes. La primera, como una forma de contextualizar la discusión, ofrece un breve análisis histórico de las cuatro olas de descolonización y una tipología de los procesos decoloniales. La segunda reflexiona sobre tres temas que estructuran los procesos de descolonización desde una perspectiva legal y política: historia, Estado y nación. Finalmente, la parte tercera reflexiona sobre estos tres temas constitutivos de la descolonización, tiempo, espacio y sujeto, con respecto a los antiguos imperios europeos. La descolonización, es importante enfatizarlo, estructura el horizonte legal y político en el cual se ubican tanto las antiguas colonias como los antiguos imperios. Las dimensiones constitucionales de los procesos descoloniales son un objeto de estudio que ha sido poco examinado por la academia jurídica. Esperamos que este artículo contribuya a abrir vetas de investigación que nos permitan describir, entender y evaluar más precisa y complejamente las aristas jurídicas que componen tales procesos.

\section{El proceso de descolonización en la historia constitucional}

\section{Las cuatro olas de descolonización}

Los historiadores contemporáneos diferencian cuatro olas en los procesos de descolonización de la modernidad clásica y tardía, cada una de las cuales produce una marea alta en la creación de constituciones en el mundo ${ }^{5}$. La primera ola se da en el nuevo mundo entre finales del siglo XVIII y la primera mitad del siglo XIX. Este es un proceso que se concreta tanto en las colonias británicas como en las españolas, portuguesas y francesas en América y el Caribe. Dos de estos procesos son paradigmáticos e influyeron de manera importante en otros procesos decoloniales: la revolución estadounidense y la revolución haitiana. La primera constituye el ejemplo paradigmático de las revoluciones liberales; la segunda, un caso excepcional, pero extraordinario, de una revolución liberal antiesclavista y liderada por hombres y mujeres negros ${ }^{6}$. Estas revoluciones, que terminan con la expedición de las constituciones de 1787 y 1801, fueron ideológicamente relevantes en las revoluciones de independencia de América Latina, tanto las de América hispanohablante como la lusohablante, que hacen parte de esta primera ola decolonial ${ }^{7}$.

La segunda ola se materializa con la disolución de los imperios de Europa continental como consecuencia de la Segunda Guerra Mundial, en particular, la caída del Imperio ruso luego del triunfo de la revolución bolchevique (1917), la disolución del Imperio de los Habsburgo como consecuencia de su derrota en la primera guerra mundial (1918), y el ocaso del Imperio otomano, por la misma causa (1922/23). Esta ola, históricamente, se ha asociado menos con los procesos decoloniales en la medida en que es un proceso que se construye de arriba hacia abajo — se concreta con los tratados de Versalles y Sèvres - y se da entre imperios y pueblos europeos. Sin embargo, en esta ola, como en las otras, se crean nuevos Estados y constituciones que dan unidad político-jurídica a pueblos como el polaco, el finlandés y el checo ${ }^{8}$.

La tercera ola se concreta en Asia y África, en el periodo comprendido entre la terminación de la Segunda Guerra Mundial y los finales de los años 70. En esta ola se crean la mayor parte de los Estados africanos y asiáticos contemporáneos, debido a la caída de los imperios británico, francés, portugués, belga y holandés. Esta es la ola que más comúnmente se asocia con la categoría descolonización. En esta ola se crean más de noventa Estados nación con sus respectivas constituciones, algunas de las cuales están todavía vigentes, por ejemplo, las constituciones de Indonesia (1945), India (1949), Malasia (1957) y Botswana (1966)9. Durante 
los años 70, las constituciones de los Estados poscoloniales constituían las 2/3 partes de las constituciones del mundo ${ }^{10}$.

Finalmente, la cuarta ola se da con la disolución del Imperio soviético en 1989. En esta ola (re)surgen un número importante de Estados independientes con nuevas constituciones en Europa del Este y central, entre otros, Estonia, Ucrania, Letonia, Lituania y Georgia ${ }^{11}$. Si se incluyen las nuevas constituciones de la cuarta ola, las constituciones de los Estados poscoloniales constituían 4/5 partes de las constituciones del mundo al final del siglo $\mathrm{XX}^{12}$.

Desde una perspectiva constitucional, las cuatro olas de descolonización se caracterizan por seguir un macropatrón común, a saber, la caída de un imperio que tiene como resultado la creación de un nuevo Estado nación fundado y regulado por una constitución. En un nivel más concreto, los procesos de descolonización muestran una profunda heterogeneidad y, por lo tanto, requieren un análisis constitucional diferenciado que tenga en cuenta las discontinuidades, así como las continuidades, que los caracterizan.

\section{Una tipología de los procesos de descolonización}

Los siguientes tres factores son fundamentales para comprender y clasificar las distintas formas que toman los procesos decoloniales: el tipo de gobierno colonial, el tipo de transición y los contextos locales ${ }^{13}$.

\section{El tipo de gobierno colonial T4}

El tipo de gobierno imperial que rigió en la colonia que se independiza es el primer tipo de gobierno imperial $^{14}$. En el gobierno imperial directo, la metrópolis exporta las estructuras jurídicas y políticas que regulan la vida pública de la colonia, así como el grueso de los funcionarios que las aplican. Las colonias portuguesas en África, entre otras, Cabo Verde, Mozambique y Angola, son un buen ejemplo de este tipo de gobierno imperial ${ }^{15}$. En el gobierno imperial indirecto, el imperio tolera algunos aspectos del sistema jurídico de la colonia, usualmente lo que se conoce como el derecho personal de las tradiciones culturales que la componen, pero controla el orden público, el comercio y relaciones internacionales, la tributación y concentra el poder jurídico y político último dentro de la colonia ${ }^{16}$. El gobierno de la colonia se materializa mediante el control de las élites locales y de sus formas de gobierno. La vida privada de los nativos es, por tanto, regulada por el derecho nativo (usualmente de corte religioso), pero los aspectos centrales de la vida pública son controlados por el derecho creado por la metrópolis. Del mismo modo, los funcionarios que ocupan las estructuras superiores de la colonia provienen de la metrópolis, pero las capas inferiores del gobierno imperial son ocupadas por los nativos. India, durante una parte importante del imperio británico, ilustra de manera paradigmática esta forma de gobierno ${ }^{17}$.

En el gobierno imperial de asentamientos, el derecho que regula la vida privada y pública de la colonia es una combinación de normas jurídicas importadas de la metrópolis por los colonos y derecho nativo, parte del cual es realmente una creación colonial, por ejemplo, la institución de los jefes de tribu en varias colonias africanas ${ }^{18}$. En el gobierno imperial de asentamientos, los colonos tienen como objetivo habitar de manera permanente la colonia y reemplazar la sociedad nativa. Esta forma de gobierno imperial, por tanto, no solo busca gobernar la colonia directa o indirectamente para obtener beneficios económicos, políticos o militares. Suráfrica es un buen ejemplo de esta forma de gobierno imperial ${ }^{19}$. 


\section{Tipo de transición}

La heterogeneidad de los procesos de descolonización es una función de la forma en que las comunidades políticas alcanzan su independencia. Algunas colonias la lograron por medio de guerras de independencia que terminan con la promulgación de una nueva constitución, por ejemplo, Argelia, Colombia, Estados Unidos y Vietnam $^{20}$. Otras mediante traspasos "pacíficos" de poder por parte de la metrópolis ${ }^{21}$. Ceylan, Cambodia y Laos son ejemplos de esta forma de descolonización. Estas formas de alcanzar la independencia, que ponen en operación dinámicas violentas, pero que no incluyen una guerra de independencia, generalmente se explican por (i) la pérdida de legitimidad internacional por parte de la metrópoli, dada la evidente contradicción entre el discurso liberal con el que está comprometido y las prácticas iliberales que materializa en las colonias; (ii) un balance costo-beneficio que muestra que económicamente no es eficiente para la metrópoli mantener la colonia; o (iii) un acuerdo entre el imperio y las élites locales que buscan evitar una revolución nacionalista en la colonia y, al mismo tiempo, que la metrópoli mantenga un grado de influencia en el nuevo Estado ${ }^{22}$.

Estas transiciones, generalmente pactadas, involucraron la promulgación de una nueva constitución negociada o impuesta por el antiguo poder colonial. Las primeras constituciones de Ghana, Kenia, Malasia y Sri Lanka, por ejemplo, fueron escritas en gran parte por funcionarios británicos y promulgadas por el parlamento británico ${ }^{23}$. La excepción en esta categoría es India: se independizó en 1947 con la Ley de Independencia de la India aprobada por el parlamento británico, pero fueron los indios quienes redactaron y promulgaron su propia constitución mediante una asamblea nacional constituyente en $1949^{24}$.

\section{Contextos locales}

Finalmente, la heterogeneidad de los procesos de descolonización es también una consecuencia de las particularidades de los contextos locales. La fragmentación o unidad política de las élites, así como su legitimidad, la fortaleza de los movimientos populares, el grado de desarrollo y fortaleza de la economía, la diversidad cultural, las relaciones entre las minorías o mayorías culturales y la fortaleza de las tradiciones nativas que sobreviven al gobierno imperial, entre otras variables, condicionan las características precisas de los procesos decoloniales ${ }^{25}$.

El proceso de descolonización de Argentina, en el siglo XIX, por ejemplo, es distinto al de India. En Argentina, para hacer referencia únicamente a una variable que diferencia los dos procesos, los sujetos coloniales tenían un grado de homogeneidad alto, dada la destrucción de gran parte de las comunidades indígenas durante la conquista y la colonia. Estas élites eran blancas o mestizas, hispanohablantes y católicas, lo que facilitaba la cohesión social y, por tanto, la acción colectiva en contra del imperio español y a favor del proceso de creación de un nuevo Estado ${ }^{26}$.

En India, la diversidad cultural y religiosa generó retos notables para la coordinación de las actividades políticas y militares en contra del imperio y para la consolidación del nuevo Estado. Estas dificultades se explicitan de manera particularmente intensa con la partición de la antigua colonia en dos: India y Pakistán ${ }^{27}$. Asimismo, esta diversidad es uno de los factores que motivó la creación de cartas de derechos en las constituciones de estas colonias británicas, aun en contra de la tradición jurídica y política imperial ${ }^{28}$. 


\section{La estructura conceptual y práctica de la descolonización: tres temas constitutivos del constitucionalismo poscolonial}

La heterogeneidad caracterizó no solo el proceso de descolonización, sino también sus consecuencias en el derecho constitucional. Sin embargo, podemos identificar tres temas estructurales que ayudan a comprender los patrones discursivos y las prácticas transversales que surgieron de los procesos de creación y desarrollo constitucional durante la descolonización: historia, Estado y nación. El primero de estos temas explora la relación entre identidad, historia y constitución. El tiempo, esto es, la definición y las relaciones entre el pasado, presente y futuro colectivo — proceso que se sintetiza paradigmáticamente en una carta políticaes central para imaginar y construir las nuevas comunidades políticas que surgen como consecuencia de los procesos decoloniales. El segundo es la creación de una geografía conceptual específica, un Estado soberano e independiente como el espacio en el que ha de constituirse la nueva comunidad política. El tercero es la emergencia de un sujeto colectivo transtemporal que habita y sirve a este Estado: la nación. Estos temas, que están estrechamente, relacionados, apuntan a las sinergias y conflictos entre la descolonización y el constitucionalismo moderno y abren espacios para futuras investigaciones en derecho y teoría constitucional comparada ${ }^{29}$.

\section{Historia, identidad y constitucionalismo}

El problema central que enfrentan las sociedades poscoloniales es imaginar y construir la nueva comunidad política independiente ${ }^{30}$. Para hacerlo, las excolonias deben tomar decisiones ineludibles desde el presente transicional sobre cómo interpretar su pasado y cómo proyectar el futuro de la colectividad ${ }^{31}$. Las excolonias deben precisar qué marcas del pasado imperial deben hacer parte de la narrativa que construirá la nueva comunidad política, así como su significado; qué partes del pasado nativo deben ser retomados y cómo deben ser interpretadas; y cómo se deben articular todas estas variables para dar sentido al futuro de la nueva comunidad política. La relación de la excolonia con la historia, por tanto, desempeña un papel fundamental en la construcción de la identidad política y jurídica de la nueva entidad colectiva. La narrativa que da forma a la individualidad de la nueva comunidad política está estrechamente relacionada con el tiempo.

En particular, para los redactores de las nuevas constituciones de las sociedades poscoloniales resulta inevitable construir una interpretación sobre la historia político-jurídica imperial. En otras palabras, tienen que decidir en qué sentido su constitución será "post” colonial, una decisión que moldeará profundamente la identidad legal y política de la nueva organización política. Esta decisión fundamental rara vez se tomó de manera tajante en un único momento preciso, más bien, fue una decisión que implicó rupturas y continuidades $^{32}$. Para las excolonias, el derecho imperial es al mismo tiempo un símbolo de la subordinación y la violencia de la metrópolis y una herramienta necesaria para cumplir objetivos básicos de la nueva comunidad política, entre otros, mantener el orden público, regular las relaciones comerciales y garantizar el funcionamiento de las burocracias. El derecho imperial, en las excolonias, sigue siendo el único derecho disponible o una parte medular del derecho que regula la vida privada y pública de los individuos ${ }^{33}$. En muchas de ellas, no hay un derecho propio que pueda reemplazar completa o parcialmente al derecho imperial. Este fue el caso de las colonias españolas y portuguesas en América Latina. Una parte central del derecho existente en el momento en el que se alcanza la independencia en países como Brasil, la Gran Colombia y Chile había sido creado por el imperio; también lo había sido en las excolonias portuguesas en África, por ejemplo, Mozambique, Cabo Verde y Angola ${ }^{34}$.

Asimismo, algunas excolonias consideran que el derecho imperial contiene apartes valiosos para cumplir los fines de la nueva comunidad política, por ejemplo, principios y reglas del derecho civil o comercial que 
son útiles para regular la vida entre las personas (obligaciones y contratos, por ejemplo) y mantener en operación el comercio doméstico e internacional (aduanas e impuestos, por ejemplo). De igual modo, los imperios ejercen presión directa o indirecta para mantener apartes de los sistemas jurídicos coloniales de manera que puedan proteger sus intereses políticos o comerciales. El imperio británico, por ejemplo, presionó para que algunas de sus excolonias promulgaran una carta de derechos de manera que, entre otras cosas, se protegieran a sus colonos o la propiedad de sus empresas ${ }^{35}$. Finalmente, las excolonias se encuentran con los límites de la imaginación jurídico-política de los individuos que las componen. Las categorías mediante las cuales interpretan la historia jurídica imperial o propia y la conectan con el futuro de la comunidad política hacen parte de la gramática del derecho moderno exportado por la metrópolis. La malla conceptual de la que dependen para la construcción de la nueva comunidad política fue exportada por el imperio y, por regla general, no existe una tradición de interpretación fuerte dentro de la excolonia. Además, el derecho local, si todavía existe, puede no ser útil para enfrentar los retos de una nueva comunidad política en la modernidad clásica o tardía.

Ahora bien, estos retos con respecto a la historia jurídico-política se agudizan radicalmente cuando se entrecruzan con las constituciones y el constitucionalismo. La constitución es un elemento central de la autobiografía moral y política que están construyendo las nuevas comunidades ${ }^{36}$. Este documento sintetiza las aspiraciones de la nueva entidad política y, por tanto, precisa las relaciones que quiere tener con el pasado jurídico-político imperial y nativo. Igualmente, establece la estructura institucional básica y los principios que permitirán que aquellas se hagan realidad. El constitucionalismo determina los patrones discursivos y prácticos que precisan las formas de aplicación y los efectos de las cartas políticas. Los dos (constituciones y constitucionalismo) están fuertemente condicionadas, sino determinadas por la gramática del constitucionalismo moderno ${ }^{37}$. La conciencia jurídico-política de las excolonias está constituida parcial o totalmente por un vocabulario particular, así como por unos principios y reglas que determinan su uso apropiado $^{38}$.

Este vocabulario está conformado por un conjunto de palabras como pueblo, ciudadano, derechos, sujeto, autonomía individual, esfera pública, esfera privada e igualdad ${ }^{39}$. Las reglas y principios que regulan su uso determinan que tipo de combinaciones son posibles para que tengan sentido en una proposición político jurídica, por ejemplo, precisan que la universalidad de la ley está en contradicción con una sociedad estamental o que la nación es anterior al Estado ${ }^{40}$. Este vocabulario y sus normas de uso son utilizados e interpretados por distintas tradiciones políticas como el liberalismo, el socialismo y el conservadurismo. Esta gramática no es de ninguna forma unívoca. No obstante, fue articulada por autores europeos paradigmáticos como Hobbes, Locke, Rousseau, Montesquieu y Kant, y ha sido históricamente interpretada por instituciones europeas o estadounidenses como el Consejo de Estado francés o la Corte Suprema de Justicia estadounidense. Las sociedades poscoloniales han permanecido en las márgenes de la construcción e interpretación de este vocabulario y gramática del constitucionalismo moderno ${ }^{41}$.

Las comunidades poscoloniales se han enfrentado a la historia constitucional imperial (y la gramática del constitucionalismo moderno que la constituye) de tres formas analíticamente distinguibles, pero que se entrecruzan en la práctica: mímesis, poiesis e hibridación. Estos usos e interpretaciones de la gramática del constitucionalismo imperial son tipos ideales que no se encuentran puros en las sociedades poscoloniales.

\section{Mimesis}

Las comunidades políticas poscoloniales miméticas son aquellas que reproducen las formas y contenidos de las constituciones y el constitucionalismo imperiales. Este proceso se describe con frecuencia como "trasplante", "préstamo" o "migración" de ideas e instituciones constitucionales ${ }^{42}$. Este proceso de intercambio de conocimiento jurídico, claro, no fue siempre voluntario. La presión de los imperios sobre las excolonias 
propias o ajenas para que los trasplantes jurídicos tuvieran como fuente sus ordenamientos jurídicos no fue la excepción. Para los imperios resultaba geopolíticamente importante dejar una impronta jurídica y política en los nuevos estados poscoloniales. Esta impronta permitiría que los lazos de dependencia jurídica y política se transformaran y al mismo tiempo se mantuvieran, por ejemplo, mediante la dependencia de los teóricos, las universidades y los textos, discursos y prácticas constitucionales de las metrópolis.

Estos procesos miméticos típicamente se dan a lo largo de los siguientes tres ejes: intraimperio, extraimperio e ideológico ${ }^{43}$. En el primer eje, las excolonias reproducen las constituciones y el constitucionalismo de su antiguo imperio. Una buena parte de las sociedades poscoloniales, por ejemplo, reprodujeron los estilos constitucionales civilista o consuetudinario con el que estaban comprometidos sus imperios. Las excolonias francesas en África tendieron a seguir los contenidos y prácticas de las constituciones y el constitucionalismo de la familia civilista: presidencialismo, elección popular del presidente y tradiciones de interpretación exegética y sistemática, por ejemplo ${ }^{44}$. Las excolonias británicas en Asia tendieron a reproducir los contenidos y prácticas de las constituciones y el constitucionalismo de la tradición consuetudinaria (parlamentarismo, bicameralismo, derechos individuales, entre otros). El sistema de Westminster se convirtió así en "Eastminster" en las nuevas constituciones de India, Sri Lanka, Malasia, Ghana, entre otras ${ }^{45}$.

En el segundo eje, las excolonias tomaron instituciones de las tradiciones constitucionales de otros imperios. La inclusión de cartas de derechos en muchas constituciones de las antiguas colonias británicas es un ejemplo paradigmático de estos procesos. India, Nigeria, Malasia, Sri Lanka, Sudán, entre otros, incluyeron cartas de derechos en sus constituciones, siguiendo la tradición de los catálogos de derechos constitucionales iniciados por la Declaración Francesa de Derechos del Hombre y la declaración de derechos de los Estados Unidos, aunque Gran Bretaña no tenía una carta de derechos escrita e inicialmente se opuso a que se incluyera en sus excolonias ${ }^{46}$. En el tercer eje, las sociedades poscoloniales reprodujeron las constituciones y el constitucionalismo de las potencias durante la guerra fría. Así, algunos países de África como Angola, Argelia, Senegal, Tanzania, Togo, Burkina Faso o Congo, que estaban en la órbita soviética, reprodujeron el constitucionalismo socialista, mientras que algunos países asiáticos, que estaban bajo la influencia estadounidense, como Vietnam del Sur o Filipinas, reprodujeron el constitucionalismo liberal ${ }^{47}$.

\section{Poiesis}

Las comunidades políticas poscoloniales poiéticas son aquellas que intentaron romper con el constitucionalismo imperial y crear un derecho constitucional propio mediante el retorno, recreación o invención de un pasado nativo anterior al arribo del imperio. Estos esfuerzos fueron principalmente discursivos o se materializaron muy parcialmente en algunas pocas instituciones o prácticas constitucionales en las sociedades poscoloniales. Las tradiciones constitucionales locales no eran útiles para enfrentar los retos de la modernidad clásica o tardía; eran tradiciones orales que se habían perdido total o parcialmente; o sus escritos canónicos habían sido olvidados por la historia local o no tenían ya suficiente legitimidad en la nueva sociedad poscolonial. Un ejemplo duradero de poiesis constitucional es el regreso a las tradiciones político-legales del islam, especialmente en el Irán revolucionario ${ }^{48}$. Otros ejemplos fueron experimentos de corta duración o solo parte de las utopías constitucionales de las excolonias, como la idea de las federaciones panafricanas o panislámicas, el movimiento de la "negritud" en África francófona, formas de autogobierno negro como los “quilombos" en Brasil o el retorno a las tradiciones jurídicas locales en India ${ }^{49}$. 


\section{Hibridación}

Finalmente, las comunidades políticas poscoloniales híbridas fueron aquellas que transformaron partes de las instituciones o prácticas del constitucionalismo moderno legados por el imperio o transplantados por las excolonias durante el proceso de articulación o consolidación de las nuevas comunidades políticas. En estos casos, las sociedades poscoloniales modifican el sentido del vocabulario del constitucionalismo moderno o dan un giro a algunas de sus reglas de uso. Un ejemplo temprano de hibridación constitucional es la Constitución de Haití de 1801: esta carta política abolió la esclavitud y emancipó a los hombres y mujeres negros a través del vocabulario del constitucionalismo liberal, mientras que al mismo tiempo instituía un ejecutivo dominante, cuasi imperial ${ }^{50}$. Otro ejemplo de hibridación son las constituciones contemporáneas en América Latina que incorporan instituciones y cosmovisiones indígenas dentro del constitucionalismo moderno, por ejemplo, la Constitución boliviana de 2008 y la Constitución ecuatoriana de $2009^{51}$.

Un último ejemplo es la hibridación del control de constitucionalidad. En muchas excolonias, los poderes judiciales siguieron siendo débiles y dependientes del ejecutivo y no impusieron límites constitucionales al gobierno, una situación descrita como "constituciones sin constitucionalismo" 52 . Otras excolonias establecieron sistemas efectivos de control de constitucionalidad, inspirados en los modelos estadounidense o europeo, pero adaptándolos a las necesidades y contextos particulares de sus sociedades. Un buen ejemplo de esta institución híbrida, que respondió a los altos niveles de desigualdad en las excolonias, es la expansión del acceso a la justicia constitucional en América Latina mediante acciones constitucionales específicas como la "tutela" o el "amparo" 53 , o mediante el litigio de interés público en India ${ }^{54}$. Como resultado de estos cambios amparados en la Constitución india, los litigios contra el Estado aumentaron exponencialmente después de la independencia. Solo durante su primer año, la Corte Suprema de la India atendió 600 recursos contra el Estado; en 1962, este número había aumentado a 3833 (en comparación con 960 casos de este tipo en la Corte Suprema de Estados Unidos en el mismo periodo) ${ }^{55}$.

En esta jurisprudencia, la Corte Suprema de la India se divide cunando discute cuestiones relacionadas con la historia, la identidad y las (dis)continuidades, temas que normalmente enfrentan los tribunales posocoloniales ${ }^{56}$. ¿Las leyes coloniales eran inválidas, como lo sostuvo el tribunal en 1954, porque "el pasado fue destruido excepto donde se preservaba expresamente [dado que], en un momento dado, nació un nuevo orden con una [exigencia de] fidelidad que brota de la misma fuente para todos, fundada en la misma base: la voluntad soberana de los pueblos de la India"? ${ }^{57}$ o ¿̇la constitución marcó "simplemente [un] cambio en la forma de gobierno", un "paso final en la evolución hacia el autogobierno" 58 ? Como resultado de tales desacuerdos judiciales, muchas leyes coloniales siguieron vigentes por décadas, por ejemplo, la Corte Suprema invalidó una ley colonial que criminalizaba la homosexualidad solo hasta $2018^{59}$.

\section{El Estado soberano e independiente}

El vocabulario y la gramática del constitucionalismo moderno también controla la manera como las sociedades poscoloniales imaginan el espacio político y jurídico que deben habitar luego de la independencia. Para las sociedades poscoloniales existir como comunidades políticas independientes implica existir como Estados nacionales. Existir en la comunidad internacional, luego del Pacto de Westphalia, implicaba articularse como un Estado independiente y soberano ${ }^{60}$. Si las sociedades poscoloniales querían entrar como pares a la comunidad internacional, aunque fuera formalmente, debían recrearse en este tipo de espacio político-jurídico; solo en la segunda mitad del siglo XX surgieron 91 Estados como consecuencia de la disolución de los imperios occidentales. Ahora bien, la dependencia conceptual de las sociedades poscoloniales con respecto al vocabulario y la gramática del constitucionalismo moderno no se limita 
únicamente a la escogencia del espacio político-jurídico que habitarán, sino también a su fundamento: los principios de soberanía y autogobierno. El Estado poscolonial se entiende como un Estado soberano (internamente supremo) e independiente (externamente no está sometido a ninguna autoridad). La gramática del constitucionalismo moderno presupone relaciones particulares entre los conceptos de Estado, autodeterminación, nación y pueblo, soberanía popular, poder constituyente y constitucionalismo.

Estas relaciones implicaban posibilidades conceptuales, así como limitaciones para las sociedades poscoloniales. Imitar al Estado europeo ofreció un camino hacia la descolonización con una teleología bien definida. También hizo explícita la incompatibilidad del imperio y la soberanía popular, y presentó un modelo de autogobierno basado en los derechos políticos que no se le habían reconocido a los sujetos coloniales en los imperios ${ }^{61}$. Al mismo tiempo, comprometerse con la estructura política y jurídica "Estado" implicaba limitaciones conceptuales y dificultades para las sociedades poscoloniales: excluía formas alternativas de organización política y autodeterminación; establecía características particulares de los Estados europeos como características universales de los Estados; e implicaba la aceptación de las fronteras coloniales y la homogeneización espacial impuesta por el Estado a la pluralidad de grupos e identidades que quedaron comprendidos en su territorio.

En primer lugar, era conceptualmente posible imaginar alternativas al Estado como punto final de la descolonización ${ }^{62}$. Las modernidades occidentales y no occidentales han imaginado diversas formas de construir una comunidad política distinta al imperio, algunas de las cuales se han materializado históricamente: desde federaciones de pueblos unidos por el compromiso con una religión pasando por el gobierno universal cosmopolita kantiano, hasta las federaciones de pueblos unidos alrededor de una cultura o la creación de la comunidad política universal proletaria. Algunos promotores de la independencia en África y Asia, por ejemplo, abrazaron el internacionalismo comunista de clase, por ejemplo, en Vietnam ${ }^{63}$. Asimismo, en India, Mahtama Gandhi abogó por un concepto de autodeterminación (bind swaraj) que dependía en gran medida de la descentralización y de la aldea como unidad de organización política ${ }^{64}$ y los movimientos panafricanos, panárabes y panislámicos buscaron canalizar la descolonización en federaciones y Estados compuestos por un sistema de soberanía en capas. Sin embargo, estas federaciones siguieron siendo experimentos de corta duración, como en el caso de la Unión de Estados Africanos (1958-1963), la Federación Centroafricana (1953-1963) o la Federación Independiente de Malaya (1957-1963) ${ }^{65}$. Ninguna de estas alternativas conceptuales se materializó en una poiesis constitucional duradera, a pesar de que influyeron en algunos arreglos híbridos, por ejemplo, el sistema panchayat del gobierno local bajo la Constitución enmendada de la India (art. 243B-O).

En segundo lugar, al comprometerse con el Estado como espacio político y jurídico también significó que la forma de Estado europea y estadounidense se convirtió en un modelo para las sociedades poscoloniales ${ }^{66}$. En el contexto europeo y estadounidense, la soberanía interna se manifiesta en forma de una constitución que organiza el sistema político de un país independiente ${ }^{67}$. Sin embargo, la mayoría de los Estados poscoloniales surgieron como Estados en desarrollo, cuya independencia política estaba severamente restringida por la dependencia continua de las relaciones económicas y políticas estructuradas por los imperios ${ }^{68}$. Esta realidad del Estado poscolonial no es capturada por un concepto de constitucionalismo político que separa el Estado y la economía, la soberanía y la propiedad, las esferas política y económica ${ }^{69}$. Mientras que algunas constituciones poscoloniales intentaron alcanzar la autodeterminación económica por medio del constitucionalismo socialista y la nacionalización económica siguiendo el camino de la Unión Soviética, otros Estados en desarrollo buscaron "modernizarse" económica y legalmente de acuerdo con el modelo de los países industrializados en Europa Occidental y América del Norte ${ }^{70}$.

En tercer lugar, la creación de un Estado también implicó la aceptación de las fronteras coloniales que las potencias imperiales habían impuesto sin tener en cuenta los límites tradicionales de las poblaciones indígenas, y el rechazo de alternativas que habrían deshecho el ordenamiento espacial colonial, como 
las federaciones basadas en variables religiosas o lingüísticas ${ }^{71}$. Los Estados poscoloniales incorporaron legalmente la violencia imperial y la homogeneización espacial impuesta por las fronteras coloniales sobre la pluralidad de identidades colectivas e individuales que vivían en el territorio gobernado por las nuevas constituciones nacionales.

\section{La invención de la nación poscolonial}

El proceso de construcción del Estado poscolonial es concomitante con la construcción del sujeto colectivo transtemporal que lo habita: la nación. Condicionada por el vocabulario y la gramática del constitucionalismo moderno, las sociedades poscoloniales se comprometen con la construcción de este sujeto culturalmente homogéneo que supuestamente debe preexistir al Estado. A cada nación le corresponde un Estado; a cada Estado una nación. Este supuesto conceptual choca en las sociedades poscoloniales, como había chocado en las sociedades occidentales en el siglo XIX y principios del siglo XX, con la diversidad cultural existente en el campo social ${ }^{72}$. A la conciencia jurídico-política poscolonial, construida en buena parte por la gramática del constitucionalismo moderno, la atraviesa una poderosa disonancia cognitiva: la unidad, cohesión y homogeneidad cultural del sujeto colectivo transtemporal imaginado coexiste en tensión con la fragmentación, la disgregación y la heterogeneidad cultural de los sujetos colectivos que efectivamente existen en el territorio. Estos sujetos colectivos, además, conviven en el espacio controlado por el estado poscolonial como consecuencia de las fronteras impuestas por el imperio.

El sujeto colectivo que se entiende como condición necesaria para la creación del espacio político por excelencia de la modernidad clásica y tardía coexiste con la pluralidad de sujetos colectivos que se resisten a su desaparición, fusión o traslapamiento. La nación nigeriana culturalmente homogénea, por ejemplo, se enfrentaba (y se enfrenta) con la existencia de aproximadamente 250 etnias que existen en el territorio de Nigeria, siendo las Hausa, Yoruba e Igbo las mayoritarias ${ }^{73}$. La nación india culturalmente homogénea estaba (y está) en tensión con las comunidades hinduistas, budistas, cristianas, jainistas, zoroastrianas, musulmanas y sikhs que coexisten dentro de la sociedad poscolonial india. Igualmente, estaba (y está) en tensión con las 630 tribus indígenas reconocidas y con las comunidades lingüísticas que hablan 114 lenguas distintas ${ }^{74}$.

En estas circunstancias, las constituciones poscoloniales se utilizaron como instrumentos para crear las condiciones que se consideran requisitos previos de su propia existencia. El constitucionalismo poscolonial se convirtió en un espacio para las prácticas que tenían como objetivo la formación de los Estados y en un proyecto, a menudo violento, de construcción de la nación ${ }^{75}$. Los intentos de imitar estrechamente al Estado nación europeo e imponer la homogeneidad por medios jurídicos contribuyeron a la discriminación, las guerras civiles, la violencia o la secesión. En los procesos de hibridación surgieron alternativas conceptuales al Estado de una sola nación, a saber, la idea de las naciones-Estado y de los Estados plurinacionales ${ }^{76}$. Institucionalmente, el federalismo, las autonomías territoriales, el pluralismo legal o el reconocimiento de los derechos lingüísticos y culturales colectivos se convirtieron en estrategias comunes para acomodar política y jurídicamente la diversidad. En el proceso, las constituciones poscoloniales también adaptaron y transformaron el concepto y la práctica de la democracia. Los procesos electorales, la representación política y los partidos políticos reflejan tanto la diversidad de las sociedades poscoloniales como la lucha contra los legados de la subordinación y la exclusión coloniales ${ }^{77}$. 


\section{Descolonizar a Europa: legados y repercusiones constitucionales en las metrópolis}

Los problemas centrales que enfrentaron las metrópolis luego de la independencia de sus colonias fueron ( $\mathrm{y}$ siguen siendo), por un lado, la transición institucional de imperios a Estados nación posimperiales y, por el otro, reimaginar su identidad constitucional a la luz de su pasado imperial. Como en las excolonias, este proceso involucraba continuidades y rupturas. En algunos casos, la descolonización implicaba el colapso de un orden constitucional imperial. En Francia, la identidad nacional había estado estrechamente vinculada a la estructura imperial consagrada en la Constitución de la Cuarta República de 1949. Las guerras decoloniales contribuyeron al colapso de este sistema y dieron lugar a creación en 1958 de la Constitución de la Quinta República, la cual incorporó los restantes territorios de ultramar en el Estado francés ${ }^{78}$. En Portugal, las repercusiones internas de la descolonización contribuyeron al derrocamiento en 1974 del régimen autoritario del Estado Novo ${ }^{79}$.

A pesar de tales rupturas constitucionales, hubo muchas continuidades en las formas y procesos por medio de las cuales las antiguas potencias imperiales reorganizaron su relación con sus excolonias y, por lo tanto, se ocuparon de su pasado y futuro jurídico y político. Las burocracias coloniales, por ejemplo, se transformaron en agencias de desarrollo que mantienen una fuerte presencia dentro de las antiguas colonias. Las antiguas colonias británicas permanecieron dentro de la Comunidad de Naciones, y aun hoy, algunas mantienen a la Reina como su jefa de Estado (por ejemplo, Australia, Canadá y Nueva Zelanda) ${ }^{80}$. Francia permaneció en una unión monetaria con África francófona, y el área de la libra esterlina británica también resistió la descolonización hasta que la integración monetaria europea se volvió más apremiante para sus intereses económicos ${ }^{81}$. Las antiguas relaciones comerciales imperiales se reorganizaron y se consagraron a nivel supranacional dentro de la Comunidad Económica Europea ${ }^{82}$.

Finalmente, para terminar con los ejemplos, los antiguos imperios, como Gran Bretaña o Francia, todavía se definen en parte, jurídica y políticamente, apelando al pasado imperial glorioso. Ese pasado es todavía un símbolo de la superioridad de sus culturas y de cómo esta superioridad redunda en la creación y difusión de un verdadero derecho constitucional o de un verdadero constitucionalismo. Argumentos como el de la tutela moral ofrecido por $\mathrm{Kant}^{83}$, de la ausencia de una noción de historia entre los no europeos presentado por Hegel $^{84}$ o la misión civilizadora de Mill $^{85}$ siguen siendo relevantes, aunque con mutaciones, para llenar de contenido y fundamentar las identidades jurídico políticas de las sociedades posimperiales ${ }^{86}$. Las discusiones sobre la identidad jurídica y política española y la leyenda negra, por ejemplo, están en el centro de algunas de las discusiones públicas más importantes de la España contemporánea ${ }^{87}$.

El derecho internacional de los derechos humanos y la justicia transicional contemporáneos también plantean preguntas sobre cómo lidiar con el pasado imperial europeo. Estos temas ilustran los desafíos relacionados con conectar y reinterpretar la historia imperial con el presente y el futuro de los Estados europeos democráticos y liberales contemporáneos. Los tribunales en Europa se han enfrentado a demandas que buscan que se reconozcan y compensen a las víctimas de la violencia colonial perpetrada en el contexto de guerras de independencia y resistencia anticolonial ${ }^{88}$. Las controversias legales también rodean la preservación o transformación de la memoria colonial en el espacio público en forma de monumentos, nombres de calles o museos ${ }^{89}$. Francia incluso ha promulgado leyes de memoria constitucionalmente controvertidas que requieren que las instituciones educativas y de investigación reconozcan ciertos aspectos positivos del colonialismo francés ${ }^{90}$.

Todos estos instrumentos o patrones discursivos y prácticos muestran que el imperio no desapareció luego de la materialización de las cuatro olas de descolonización; solo mutó. Estos instrumentos reproducen, reconfiguradas, las relaciones colonia-metrópolis. Estas dinámicas, en ocasiones se asumen en la metrópoli 
como moral y políticamente justificadas, por ejemplo, por los partidos de extrema derecha en Francia o España ${ }^{91}$, y en otras como una contradicción entre el discurso liberal que defiende la metrópoli neocolonial y sus prácticas ${ }^{92}$. No obstante, en cualquier caso, desempeñan un papel notable en la creación de los contenidos que configuran las identidades constitucionales de las sociedades posimperiales.

\section{Conclusión}

En suma, la decolonialidad es un proceso caracterizado a la vez por continuidades y discontinuidades, por dinámicas macrohomogéneas y dinámicas micro profundamente heterogéneas. Las continuidades conceptuales y prácticas se estructuran alrededor del drama que enfrentan las sociedades poscoloniales: imaginar y construir una nueva comunidad política. Este proceso se articula alrededor de tres ejes fundamentales: tiempo, espacio y sujeto. El primero exige tomar decisiones con respecto a la manera como el pasado imperial y nativo se articula en el presente y el futuro político-jurídico de la nueva comunidad. Este eje, no hay que olvidarlo, es también importante en los procesos de construcción y reinterpretación de las identidades de los Estados postimperiales. Ahora bien, este proceso de construcción de la identidad político-jurídico de las sociedades poscoloniales se entrecruza con el constitucionalismo moderno. El símbolo por excelencia de que existe un nuevo Estado-nación es la promulgación de una nueva constitución. La diversidad de los contenidos de las constituciones poscoloniales es notable. No obstante, todos estos contenidos están vaciados sobre las mismas estructuras conceptuales: el vocabulario y la gramática del constitucionalismo moderno. Estas dos variables conforman a la vez límites y oportunidades para los Estados poscoloniales. El constitucionalismo moderno los construye, pero al mismo tiempo es construido por ellos. El constitucionalismo moderno ya es parte de los Estados poscoloniales y estos lo han transformado de diversas maneras ricas e innovadoras.

El segundo eje exige construir una geografía conceptual y material en la que habitará a la sociedad poscolonial. Históricamente, las sociedades posocoloniales escogieron el Estado soberano e independiente para cumplir con este objetivo, aunque, al menos teóricamente, disponían de otras alternativas para hacerlo. El tercero es la construcción del sujeto colectivo que habitará este tipo de Estado. Históricamente, las sociedades poscoloniales escogieron la nación como el tipo de sujeto colectivo que debían construir. El imperialismo, sin embargo, no terminó con la disolución de los imperios. El imperialismo solo se transformó, reencarnó en estructuras o procesos formales e informales como el mercantilismo, la economía neoclásica globalizada, los programas de desarrollo y los proyectos de consolidación del Estado de derecho alrededor de los cuales gira la comunidad internacional en el siglo XXI. Las dimensiones constitucionales de estos procesos de transformación imperial, no obstante, deberán ser objeto de futuras investigaciones.

\section{Bibliografía}

Adam J. Barker, Locating Settler Colonialism, 13 Journal of Colonialism and Colonial History 1-18 (2012).

Adom Getachew, Worldmaking after Empire. The Rise and fall of Self-Determination (Princeton University Press, 2019).

Aimé Cesaire, Toussaint Louverture. La Re\#volution Franc\#aise Et Le Proble\#me Colonial (Présence africaine, 1961). Alan Watson, Legal Transplants. An Approach to Comparative Law (University of Georgia Press, 1974).

Alfred W. B. Simpson, Human Rights and the end of Empire. Britain and the Genesis of the European Convention, 924 (Oxford University Press, 2010)

Alpana Roy, Postcolonial Theory and Law: A Critical Introduction, 29 Adelaide Law Review 315-357 (2008).

Antonio Carlos Wolkmer \& Ivone Fernandes Morcilo Lixa, Constitucionalismo, descolonización y pluralismo jurídico en América Latina (Centro de Estudios Juri\#dicos y Sociales Mispat, 2015). 
Anuj Bhuwania, Courting the People. Public Interest Litigation in Post-Emergency India (Cambridge University Press, 2017).

Archives. Colonial Conspiracy or Bureaucratic Bungle?, 39 (5) The Journal of Imperial and Commonwealth History699-716.

José-Manuel Barreto, Decolonial Thinking and the Quest for Decolonising Human Rights, 46 (4-5) Asian J. Soc. Sci.484-502 (2018).

Anderson Benedict, Imagined Communities. Reflections on the Origin and Spread of Nationalism (Verso, 2006).

Boaventura de Sousa Santos, Refundación del estado en América Latina. Perspectivas desde una epistemología del sur (Siglo del Hombre Eds., 2010).

Charles Parkinson, Bills of Rights and Decolonization. The Emergence of Domestic Human Rights Instruments in Britain's Overseas Territories (Oxford University Press, 2007).

Charles Parkinson, British Constitutional Thought and the Emergence of Bills of Rights in Britain's Overseas Territories in Asia at Decolonisation, en H. Kumarasingham, ed., Constitution-making in Asia: Decolonisation and StateBuilding in the Aftermath of the British Empire (Routledge, 2016).

Dane Kennedy, Decolonization. A Very Short Introduction 5 (Oxford University Press, 2016).

Daniel Bonilla Maldonado, The Political Economy of Legal Knowledge, en Daniel Bonilla \& Colin Crawford, eds., Constitutionalism in the Americas (Edward Elgar, 2018b).

Daniel Bonilla Maldonado, Does Nature Have Rights? Cultural Diversity, the Rights of Nature and a New Constitutional Environmental Law in Latin America, en James May and Erin Daly, eds., Encyclopedia of Human Rights and the Environment: Indivisibility, Dignity and Legality (Edward Elgar, 2018a).

Daniel Bonilla Maldonado, Introduction: Toward a Constitutionalism of the Global South, en Constitutionalism of the Global South. The Activist Tribunals of India, South Africa, And Colombia, en Daniel Bonilla Maldonado, ed., 1-38 (Cambridge University Press, 2013).

Daniel Bonilla Maldonado, Legal Barbarians (Cambridge University Press, 2021).

David M. Anderson, Mau Mau in the High Court and the 'Lost' British Empire Archives: Colonial Conspiracy or Bureaucratic Bungle? 39, 5 Journal of Imperial and Commonwealth History 699-716 (2011).

David Strang, Global Patterns of Decolonization, 1500-1987, 35 International Studies Quarterly 429-454, 429-430 (1991).

David Strang, The Inner Incompatibility of Empire and Nation. Popular Sovereignty and Decolonization, 35, 2 Sociological Perspectives 367-384 (1992).

David Trubek \& Marc Galanter, Scholars in Self-Estrangement: Some Reflections on the Crisis in Law and Development Studies in the United States, 4 Wisconsin Law Review 1062-1102 (1974).

Diane Otto, Postcolonialism and Law?, 15 Third World Legal Studies vii-xviii (1999).

Dieter Schröder, Europa und die Assoziierten in Übersee. Zum völkerrechtlichen Begriff der Assoziation, 10 VRÜ / World Comparative Law 125-131 (1977).

Dirk Moses, Marco Duranti \& Roland Burke, Decolonization, Self-Determination, and the Rise of Global Human Rights Politics (Cambridge University Press, 2020).

Donald Bruce Marshall, The French Colonial Myth and Constitution-Making in the Fourth Republic (Yale University Press, 1973).

Douglas Greenberg, Stanley Nider Katz, Melanie Beth Oliviero \& Steven C. Wheatley, eds., Constitutionalism and Democracy. Transitions in the Contemporary World 65-83 (Oxford University Press, 1993).

Elizabeth Buettner, Europe after Empire. Decolonization, Society, and Culture (Cambridge University Press, 2016).

Elizabeth Kolsky, Colonial Justice in British India. White Violence and the Rule of Law (Cambridge University Press, 2010).

Erez Manela, The Wilsonian Moment: Self-Determination and the Origins of Anticolonial Nationalism (Oxford University Press, 2009). 
Erik Green, Indirect Rule and Colonial Intervention. Chiefs and Agrarian Change in Nyasaland, ca. 1933 to the Early 1950s, 44 International Journal of African Historical Studies 249-274 (2011).

Francis Mading Deng, Identity, Diversity, and Constitutionalism in Africa (United States Institute of Peace, 2008)

G. van der Tang, Documentary Constitutions - Notas Concerning a Comparative Inquiry, 9, 1 Vrü / World Comparative Law 19-31 (1976).

Gautam Bhatia, The Transformative Constitution. A Radical Biography in Nine Acts (Harper Collins, 2019).

Giuliano Garavini, After Empires. European Integration, Decolonization, and the Challenge from the Global South 1957-1986 (Oxford University Press, 2012).

Gurpreet Mahajan, Indian Exceptionalism or Indian Model: Negotiating Cultural Diversity and Minority Rights in a Democratic Nation-State, en Baogang He y Will Kymlicka, eds., Multiculturalism in Asia 288-313 (Oxford University Press, 2005).

Harshan Kumarasingham, Eastminster - Decolonisation and State-Building in British Asia, en Harshan Kumarasingham, ed., Constitution Making in Asia. Decolonisation and State-Building in the Aftermath of the British Empire 1-35 (2016b).

Harshan Kumarasingham, ed., Constitution Making in Asia. Decolonisation and State-Building in the Aftermath of the British Empire (Routledge, 2016a).

Harshan Kumarasingham, Written Differently: A Survey of Commonwealth Constitutional History in the Age of Decolonisation, 46, 5 The Journal of Imperial and Commonwealth History 874-908 (2018).

J. B. Ojwang, The Nature and Scope of Executive Power in English and French-Speaking Africa. A Comparative Perspective, 13 VRÜ / World Comparative Law 319-340 (1980).

James Fowkes \& Michaela Hailbronner, Decolonizing Eastern Europe: A global perspective on 1989 and the world it made, 17 International Journal of Constitutional Law 497-509 (2019).

James Tully, Strange Multiplicity. Constitutionalism in an Age of Diversity 62-79, Cambridge University Press (Cambridge, 1995).

Jan Kleinheisterkamp, Development of Comparative Law in Latin America, en Reinhard Zimmermann \& Mathias Reimann, eds., The Oxford Handbook of Comparative Law 261-301 (Oxford University Press, 2006).

Jeremy Adelman, Sovereignty and Revolution in the Iberian Atlantic (Princeton University Press, 2009).

José-Manuel Barreto, Imperialism and Decolonization as Scenarios of Human Rights History, en José-Manuel Barreto, ed., Human Rights from a Third-World Perspective: Critique, History and International Law (Cambridge Scholars Publishing, 2013).

José-Manuel Barreto, Strategies for Decolonization and Dialogue in the Human Rights Field. A Manifesto, 3 Transnational Legal Theory 1-29 (2012).

Judith Hackmack, Colonial repercussions in Germany and Namibia (Völkerrechtsblog, 2019).

Julian Go, A Globalizing Constitutionalism? Views from the Postcolony, 1945-2000, 18 International Sociology 71-95 (2003).

Kanad Bagchi, Transformative Constitutionalism, Constitutional Morality and Equality. The Indian Supreme Court on Section, 513 Vrü / World Comparative Law 367-380, 377 (2018).

Kwasi Prempeh, Africa's "Constitutionalism Revival": False Start or New Dawn?, 53 International Journal of Constitutional Law 469-506 (2007).

Linda Camp Keith \& Ayo Ogundele, Legal Systems and Constitutionalism in Sub-Saharan Africa: An Empirical Examination of Colonial Influences on Human Rights, 29, 4 Human Rights Quarterly 1065-1097 (2007).

Luis Eslava, The Developmental State: Independence, Dependency, and History of the South, en Philipp Dann \& Jochen v. Bernstorff, eds., The Battle For International Law In The Decolonization Era 71-100, Oxford University Press, Oxford (2019).

Manuel José Cepeda-Espinosa, Judicial Activism in a Violent Context: The Origin, Role, and Impact of the Colombian Constitutional Court, 3 Washington University Global Studies Law Review, 4, 529-700, 552-554 (2004). 
Margaret Kohn \& Keally D. McBride, Political Theories of Decolonization. Postcolonialism and the Problem of Foundations (Oxford University Press, 2011).

Matthew Campbell Mirow, Latin American Constitutions. The Constitution of Cádiz and its Legacy in Spanish America (Cambridge University Press, 2015).

Michael H. Fisher, Indirect Rule in the British Empire: The Foundations of the Residency System in India (1764-1858), 18, 3 Modern Asian Studies 393-428 (1984).

Michael Riegner, Comparative Foreign Relations Law between Centre and Periphery. Liberal and Postcolonial Perspectives, en Helmut Aust y Thomas Kleinlein, eds., Encounters between Foreign Relations Law and Public International Law. Bridges and Boundaries 60-85 (Cambridge University Press, 2020a).

Michael Riegner, Postkoloniale Erinnerungspolitik im deutschen Recht en Jochen v. Bernstorff, Philipp Dann e Isabel Feichtner, eds., Postkoloniale Rechtswissenschaftsgeschichte (en proceso de publicación) (2020b).

Mohandas Gandhi, Gandhi: 'Hind Swaraj' and Other Writings, Cambridge University Press, Cambridge (1909/2007).

Morten Broberg, The EU's Legal Ties with its Former Colonies: When Old Love Never Dies, n. ${ }^{\circ}$ 2011:01 Working Paper 4-18 (Danish Institute for International Studies, 2011).

Mostafa Rejai \& Cynthia H. Enloe, Nation-States and State-Nations, 13 International Studies Quarterly 140-158 (1969).

Nicholas White, Business and the Politics of Decolonization: The British Experience in the Twentieth Century, 53 Economic History Review 544-564 (2000).

Nilda Garay Montañe, La revolución haitiana en los inicios del constitucionalismo. La cuestión de la raza y el sujeto jurídico y político, 15 Historia constitucional 279-310, 280 (2014).

Okoth-Ogendo, Constitutions without Constitutionalism: Reflections on an African Political Paradox, en Douglas Greenberg, Stanley Nider Katz, Melanie Beth Oliviero \& Steven C. Wheatley, eds., Constitutionalism and Democracy. Transitions in the Contemporary World (Oxford University Press, 1993).

Philip Kaisary, Hercules, the Hydra, and the 1801 Constitution of Toussaint Louverture, 12 Atlantic Studies 393-411 (2015)

Philipp Dann \& Arun Thiruvengadam, eds., Democratic Constitutionalism in Continental Polities: EU and India Compared (Edward Elgar, 2021).

Philipp Dann y Felix Hanschmann, Post-Colonial Theories and Law, 45 Vrü / World Comparative Law 123-127 (2012).

Roberto Gargarella, Latin American Constitutionalism, 1810-2010. The Engine Room of the Constitution (Oxford University Press, 2013).

Rohit De, A People's Constitution. The Everyday Life of Law in the Indian Republic (Princeton University Press, 2018).

Rohit De, Rebellion, Dacoity, and Equality: The Emergence of the Constitutional Field in Postcolonial India, 34, 2 Comparative Studies Of South Asia, Africa and the Middle East 260-278 (2014).

Ruth Craggs \& Harshan Kumarasingham, Losing an Empire and Building a Role: The Queen, Geopolitics and the Construction of the Commonwealth Headship at the Lusaka Commonwealth Heads of Government Meeting, 1979, 43, 5 The Journal of Imperial And Commonwealth History 80-98 (2015).

Sherally Munshi, Comparative Law and Decolonizing Critique, 65 American Journal of Comparative Law 207-235 (2017).

Siddharth de Souza, India's Parallel Justice Systems: Engaging with Lok Adalats, Gram Nyayalayas, Nari Adalats and Khap Panchayats Through Human Rights, en Satvinder S. Juss, ed., Human Rights in India 80-102 (2020).

Stanley Smith, The New Commonwealth and its Constitutions (Stevens \& Sons, 1964).

Stephen J. Collier, The Commonwealth Immigrants Act of 1968, 2 Vrü / World Comparative Law 457-468 (1969).

Sujit Choudhry, Migration as a New Metaphor in Comparative Constitutional Law en Sujit Choudhry, ed., The Migration of Constitutional Ideas (Cambridge University Press, 2006).

Sujit Choudhry, What is Transformative Constitutionalism?, en Philipp Dann, Michael Riegner y Maxim Bönnemann, eds., The Global South in Comparative Constitutiona. Law (en proceso de publicación) (Oxford University Press, 2020). 
Sylvester Ogoh Alubo, Ethnic Conflicts and Citizenship Crises in the Central Region (Programme on Ethnic and Federal Studies, 2006).

Tom Ginsburg, Eastphalia as the Perfection of Westphalia, 17 Indiana Journal of Global Legal Studies 27-45 (2010).

Udit Bhatia, The Indian Constituent Assembly (Routledge, 2017).

Uladzislau Belavusau \& Aleksandra Gliszczyńska-Grabias, Introduction: Memory Laws: Mapping a new Subject in Comparative Law and Transitional Justice, en Uladzislau Belavusau \& Aleksandra Gliszczyńska-Grabias, eds., Law and Memory. Towards Legal Governance of History 1 (Cambridge University Press, 2017).

Upendra Baxi, Constitutionalism as a Site of State Formative Practices, 21 Cardozo Law Review 1183-1210, 1184-1185 (1999-2000).

Upendra Baxi, Postcolonial legality, en Henry Schwarz \& Sangeeta Ray, eds., A Companion to Postcolonial Studies 540-555 (John Wiley \& Sons, 2005).

Upendra Baxi, Postcolonial Legality. A Postscript from India, 45 Vrü / World Comparative Law 178-194, 178, 183-185 (2012).

Upendra Baxi, Taking Suffering Seriously: Social Action Litigation in the Supreme Court of India, 4 Third World Legal Studies 107-132 (1985).

Yasmin Khan, The Great Partition: The Making of India and Pakistan (Yale University Press, 2007).

Yuko Miki, Fleeing into slavery: The Insurgent Geographies of Brazilian Quilombolas (Maroons), 1880-1881, 68, 4 The Americas 495-528 (2012).

\section{Notas}

* Artículo de investigación científica. Artículo de investigación creado en el marco de un proyecto sobre descolonización y derecho constitucional.

1 David Strang, Global Patterns of Decolonization, 1500-1987, 35 International Studies Quarterly 429-454, 429-430 (1991); Dane Kennedy, Decolonization. A Very Short Introduction 5 (Oxford University Press, 2016).

2 Upendra Baxi, Constitutionalism as a Site of State Formative Practices, 21 Cardozo Law Review 1183-1210, 1184-1185 (1999-2000).

3 Maxim Bönnemann \& Laura Jung, Critical Legal Studies and Comparative Constitutional Law, en Rüdiger Wolfrum, ed., Max Planck Encyclopedia Of Comparative Constitutional Law (Oxford University Press, 2017); Alpana Roy, Postcolonial Theory And Law: A Critical Introduction, 29 Adelaide Law Review 315-357 (2008); Diane Otto, Postcolonialism and Law?, 15 Third World Legal Studies vii-xviii (1999).

4 José-Manuel Barreto, Decolonial Strategies and Dialogue in the Human Rights Field: A Manifesto, 3 Transnational Legal Theory 1-29 (2012); y José-Manuel Barreto, ed., Human Rights From A Third World Perspective. Critique, History And International Law (Cambridge Scholars Publishing, 2013).

5 Dane Kennedy, supra nota 1, págs. 5, 8.

6 Véase, por ejemplo, Constitución de Haití de 1801, "Art. 3.- No pueden existir esclavos en este territorio, la servidumbre queda abolida para siempre. Todos los hombres nacen, viven y mueren libres y franceses"; "Art. 4. - Todos los hombres, independientemente de su color, son elegibles para todos los empleos"; y "Art. 5.- No existirán distinciones más que las basadas en la virtud y el talento, y en otras ventajas que la ley otorgue en el ejercicio de una función pública. La ley es la misma para todos, ya sea que castigue o proteja”. Philip Kaisary, Hercules, the Hydra, and the 1801 Constitution of Toussaint Louverture, 12 Atlantic Studies 393-411 (2015); Nilda Garay Montañe, La revolución haitiana en los inicios del constitucionalismo. La cuestión de la raza y el sujeto jurídico y político, 15 Historia constitucional 279-310, 280 (2014); Aimé Cesaire, Toussaint Louverture. La Re\#volution Franc\#aise Et Le Proble\#me Colonial (Présence africaine, 1961).

7 Roberto Gargarella, Latin American Constitutionalism, 1810-2010. The Engine Room Of The Constitution (Oxford University Press, 2013); Jeremy Adelman, Sovereignty And Revolution In The Iberian Atlantic (Princeton University Press, 2009).

8 Dane Kennedy, supra nota 1, págs. 14-22.

9 Harshan Kumarasingham, ed., Constitution Making in Asia. Decolonisation and State-Building in the Aftermath of the British Empire (Routledge, 2016).

10 Julian Go, A Globalizing Constitutionalism?, 18 International Sociology 71-95 (2003).

11 James Fowkes \& Michaela Hailbronner, Decolonizing Eastern Europe: A globalperspective on 1989 and the world it made, 17 International Journal Of Constitutional Law, 497-509 (2019). 
12

Upendra Baxi, Postcolonial Legality. A Postscript From India, 45 Vrü / World Comparative Law 178-194, 178, 183-185 (2012).

14 Upendra Baxi, Postcolonial Legality, en Henry Schwarz \& Sangeeta Ray, eds., John Wiley \& Sons, A Companion To Postcolonial Studies 540-555 (2005).

15 Upendra Baxi, supra nota 13, pág. 183.

16 Erik Green, Indirect Rule and Colonial Intervention. Chiefs and Agrarian Change in Nyasaland, ca. 1933 to the Early 1950s, 44 International Journal Of African Historical Studies 249-274 (2011).

17 Michael H. Fisher, Indirect Rule in the British Empire: The Foundations of the Residency System in India (1764-1858), 18, 3 Modern Asian Studies 393-428 (1984).

18 Erik Green, supra nota 16.

19 Adam J. Barker, Locating Settler Colonialism, 13 Journal of Colonialism and Colonial History 1-18 (2012).

20 Dane Kennedy, supra nota 1, pág. 53.

21 Id., pág. 65.

22 Id., pág. 66.

23 Rohit De, A People's Constitution. The Everyday Life of Law in The Indian Republic 2 (Princeton University Press, 2018); Charles Parkinson, Bills of Rights and Decolonization. The Emergence of Domestic Human Rights Instruments in Britain's Overseas Territories (Oxford University Press, 2007).

24 Gautam Bhatia, The Transformative Constitution. A Radical Biography in Nine Acts (Harper Collins (2019).

25 Charles Parkinson, supra nota 23, págs. 10 y ss.

26 Roberto Gargarella, supra nota 7, págs. 1 y ss.

27 Yasmin Khan, The Great Partition: The Making of India and Pakistan (Yale University Press, 2007).

28 Charles Parkinson, supra nota 23.

29 Sherally Munshi, Comparative Law and Decolonizing Critique, 65 American Journal of Comparative Law 207-235 (2017).

30 Margaret Kohn \& Keally D. McBride, Political Theories of Decolonization. Postcolonialism and the Problem of Foundations (Oxford University Press, 2011).

31 Roberto Gargarella, supra nota 7, pág. 2.

32 Upendra Baxi, supra nota 13.

33 Para el caso paradigmático de India, véase Elizabeth Kolsky, Colonial Justice in British India. White Violence and the Rule of Law (Cambridge University Press, 2010).

34 Jan Kleinheisterkamp, Development of Comparative Law in Latin America, en The Oxford Handbook Of Comparative Law, en Reinhard Zimmermann \& Mathias Reimann, eds., 261-301 (Oxford University Press, 2006).

35 Harshan Kumarasingham, supra nota 9.

36 Adeno Addis, Constitutional Preambles as Narratives of Peoplehood, 12 Vienna Journal of International Constitutional Law 125-181 (2018); y Tom Ginsburg, Nick Foti \& Daniel Rockmore, "We the Peoples": "The Global Origins of Constitutional Preambles”, 46 George Washington International Law Review 101-135 (2014),

37 Daniel Bonilla Maldonado, Introduction: Toward a Constitutionalism of the Global South, en Constitutionalism of the Global South. The Activist Tribunals of India, South Africa, and Colombia, 1-38, Daniel Bonilla Maldonado, Ed., Cambridge University Press, Cambridge (2013).

38 Id.

39 James Tully, Strange Multiplicity. Constitutionalism in an Age of Diversity 62-79 (Cambridge University Press, 1995).

40 Daniel Bonilla Maldonado, The political economy of legal knowledge, en Colin Crawford \& Daniel Bonilla Maldonado, eds., Constitutionalism in the Americas 29-79 (Edward Elgar Publishing, 2018).

41 James Tully, supra nota 36.

42 Sujit Choudhry, ed., The migration of constitutional ideas (2010); Alan Watson, Legal transplants. An approach to comparative law (1974/1993).

43 Julian Go, supra nota 10, págs. 73-78.

44 Véase, por ejemplo, la Constitución de Argelia de 1989, Título 2. organización de los poderes capítulo I. El poder ejecutivo art. 84 El Presidente de la República, Jefe de Estado, encarnará la unidad de la Nación. Será garante de la constitución. Encarnará al Estado dentro del país y en el exterior. Se reservará el derecho de dirigirse directamente a la Nación. Art. 85 El Presidente de la República será elegido por sufragio universal, directo y secreto". Véanse, también, Linda Camp Keith \& Ayo Ogundele, Legal Systems and Constitutionalism in Sub-Saharan Africa: An Empirical Examination of Colonial Influences on Human Rights, 29, 4 Human Rights Quarterly 1065-1097 (2007); Julian Go supra nota 10; J. B. Ojwang, The Nature and Scope of Executive Power in English and French-Speaking Africa. A Comparative Perspective, 13 Vrü / World Comparative Law 319-340 (1980). 
45 Véanse, por ejemplo, la Constitución de la República de Ghana de 1960, Parte IV, Parlamento, artículos 20 al 25; véase, también, la Ley de Independencia de Ghana de 1957, "Primer Anexo, Poderes Legislativos de Ghana, Artículo 2. Ninguna ley ni disposición de ley alguna promulgada en o después del día designado por el Parlamento de Ghana será nula o inoperante sobre la base de que repudia a la ley de Inglaterra" y el "Artículo 3. El Parlamento de Ghana tendrá plenos poderes para dictar leyes con funcionamiento extraterritorial”. Asimismo, véanse Harshan Kumarasingham, ed. Eastminster - Decolonisation and State-Building in British Asia, en Harshan Kumarasingham, ed., Constitution Making in Asia. Decolonisation and State-Building in the Aftermath Of The British Empire (2016); Stanley Smith, The New Commonwealth and its Constitutions (Stevens \& Sons, 1964).

46 Véase, por ejemplo, el capítulo III, Derechos fundamentales de la Constitución de Nigeria de 1963. Esta Declaración de Derechos incluye derechos como la libertad de conciencia (art. 24), la libertad de expresión (art. 25), la libertad de movimiento (art. 27) y la no discriminación (art. 28). Igualmente, véanse, Dirk Moses, Marco Duranti \& Roland Burke, Decolonization, Self-Determination, And The Rise Of Global Human Rights Politics (Cambridge University Press, 2020); Charles Parkinson, supra nota 23.

47 Véase, por ejemplo, la Constitución de Bangladesh de 1972. Preámbulo: "Nosotros, el pueblo de Bangladesh, habiendo proclamado nuestra independencia el 26 de marzo de 1971 y, mediante una lucha histórica por la liberación nacional, establecida la independiente y soberana República Popular de Bangladesh; Prometemos que los altos ideales del nacionalismo, socialismo, democracia y laicismo, que inspiraron a nuestro heroico pueblo a dedicarse a la lucha de liberación nacional, y a nuestros valientes mártires a sacrificar sus vidas en ella, serán los principios fundamentales de la Constitución; prometemos, además, que será un objetivo fundamental del Estado lograr por medio del proceso democrático una sociedad socialista, libre de explotación, una sociedad en la que el Estado de derecho, los derechos humanos fundamentales y la libertad, la igualdad y la justicia política, económica y social, estarán asegurados para todos los ciudadanos". Véase, también, Julian Go, supra nota 10, págs. 76-77.

48 Margaret Kohn \& Keally D. McBride, supra nota 30, págs. 35 y ss.

49 Id., págs. 18 y ss.; Siddharth de Souza, India’s Parallel Justice Systems: Engaging With Lok Adalats, Gram Nyayalayas, Nari Adalats And Khap Panchayats Through Human Rights, en Satvinder S. Juss, ed., Human Rights in India, 80-102 (2020); Yuko Miki, Fleeing into slavery: The Insurgent Geographies of Brazilian Quilombolas (Maroons), 1880-1881, 68, 4 The Americas 495-528 (2012).

$50 \quad$ Philip Kaisary, supra nota 6; Aimé Cesaire, supra nota 6.

51 Véase, por ejemplo, el artículo 8 de la Constitución boliviana de 2009, "El Estado asume y promueve como principios ético-morales de la sociedad plural: ama qhilla, ama llulla, ama suwa (no seas flojo, no seas mentiroso ni seas ladrón), suma qamaña (vivir bien), ñandereko (vida armoniosa), teko kavi (vida buena), ivi maraei (tierra sin mal) y qhapaj ñan (camino o vida noble)"; y el art. 71 de la Constitución ecuatoriana de 2008, "La naturaleza o Pacha Mama, donde se reproduce y realiza la vida, tiene derecho a que se respete integralmente su existencia y el mantenimiento y regeneración de sus ciclos vitales, estructura, funciones y procesos evolutivos. Toda persona, comunidad, pueblo o nacionalidad podrá exigir a la autoridad pública el cumplimiento de los derechos de la naturaleza. Para aplicar e interpretar estos derechos se observarán los principios establecidos en la Constitución, en lo que proceda. El Estado incentivará a las personas naturales y jurídicas, y a los colectivos, para que protejan la naturaleza, y promoverá el respeto a todos los elementos que forman un ecosistema”. Véanse, también, Daniel Bonilla Maldonado, The Rights of Nature and a New Constitutional Environmental Law, en Human Rights And The Environment. Legality, Indivisibility, Dignity And Geography, en James R. May \& Erin Daly, eds. (Edward Elgar Publishing, 2019); Antonio Carlos Wolkmer \& Ivone Fernandes Morcilo Lixa, Constitucionalismo, descolonización y pluralismo jurídico en América Latina (Centro de Estudios Juri\#dicos y Sociales Mispat, 2015).

52 Okoth-Ogendo, Constitutions Without Constitutionalism: Reflections on an African Political Paradox, en Douglas Greenberg, Stanley Nider Katz, Melanie Beth Oliviero \& Steven C. Wheatley, eds., Constitutionalism And Democracy. Transitions In The Contemporary World (Oxford University Press, 1993); véase, también, Kwasi Prempeh, Africa's "Constitutionalism Revival": False Start or New Dawn?, 5, 3 International Journal Of Constitutional Law 469-506 (2007); G. van der Tang, Documentary Constitutions - Notas Concerning a Comparative Inquiry, 9, 1 Vrü / World Comparative Law 19-31 (1976).

53 Manuel José Cepeda-Espinosa, Judicial Activism in a Violent Context: The Origin, Role, and Impact of the Colombian Constitutional Court, 3, 4 Washington University Global Studies Law Review 529-700, 552-554 (2004).

54 Upendra Baxi, Taking Suffering Seriously: Social Action Litigation in the Supreme Court of India, 4 Third World Legal Studies 107-132 (1985); Anuj Bhuwania, Courting The People. Public Interest Litigation in Post-Emergency India (Cambridge University Press, 2017).

55 Rohit De, supra nota 23, págs. 10-11.

56 Rohit De, Rebellion, Dacoity, and Equality: The Emergence of the Constitutional Field in Postcolonial India, 34, 2 Comparative Studies Of South Asia, Africa And The Middle East 260-278 (2014).

57 Cf. Gautam Bhatia, supra nota 24, pág. xix.

58 Id. 
59 Sujit Choudhry, Postcolonial Proportionality: Johar, Transformative Constitutionalism and Same Sex Rights in India, en Philipp Dann, Michael Riegner \& Maxim Bönnemann, eds., The Global South And Comparative Constitutional Law 190-209 (Oxford University Press, 2020); Kanad Bagchi, Transformative Constitutionalism, Constitutional Morality and Equality. The Indian Supreme Court on Section, 51, 3 Vrü / World Comparative Law 367-380, 377 (2018).

60 Véase, por ejemplo, el artículo 1.1 de la Constitución de Mongolia de 1992 (enmendada en 2001), "Mongolia es una República independiente y soberana”; Artículo 1 de la Constitución de Ucrania de 2004 (modificada en 2019): "Ucrania es un Estado soberano e independiente, democrático, social y basado en el derecho"; Artículo 1 de la Constitución de Botswana de 1966, "CAPÍTULO I. LA REPÚBLICA (SS 1-2) 1. DECLARACIÓN DE LA REPÚBLICA Botswana es una República soberana”; así como su artículo "30. OFICINA DE PRESIDENTE Habrá un Presidente de la República de Botswana que será el Jefe de Estado"; el artículo 3 de la Constitución de Camboya de 1993, que establece que "El Reino de Camboya es un estado indivisible"; y el artículo 2.1 de la Constitución de Camerún de 1972: "La República de Camerún será un Estado unitario descentralizado. Será uno e indivisible, laico, democrático y dedicado al servicio social". Véase, también, Dane Kennedy, supra nota 1, pág. 69.

61 David Strang, The Inner Incompatibility of Empire and Nation. Popular Sovereignty and Decolonization, 35, 2 Sociological Perspectives 367-384 (1992); Margaret Kohn \& Keally D. McBride, supra nota 30, págs. 14 ss, 55 ss; Rohit De, supra nota 23, pág. 5.

62 Adom Getachew, Worldmaking After Empire. The Rise And Fall Of Self-Determination (Princeton University Press, 2019).

63 Dane Kennedy, supra nota 1, págs. 74-76.

64 Mohandas Gandhi, Gandhi: 'Hind Swaraj' and Other Writings, Cambridge University Press, Cambridge (1909/2007).

65 Margaret Kohn \& Keally D. McBride, supra nota 30, pág. 18 y ss.; Dane Kennedy, supra nota 1, págs. 76-78.

66 Tom Ginsburg, Eastphalia as the Perfection of Westphalia, 17 Indiana Journal of Global Legal Studies 27, 27-45 (2010); Dane Kennedy, supra nota 1, págs. 69 y ss.

67 Estos Estados poscoloniales se imaginan como sometidos a una constitución. La carta política se entiende como la norma suprema en el sistema jurídico del nuevo estado, aunque sus contenidos varíen, típicamente alrededor de los ejes ideológicos socialista/liberal. En América Latina, en la primera ola de descolonización, por ejemplo, todos los Estados poscoloniales promulgaron una constitución luego de independizarse. Todas estas constituciones, además, giraron alrededor de tres interpretaciones de la gramática del constitucionalismo moderno: la conservadora, la republicana y la liberal. Igualmente, para seguir con los ejemplos, los 91 Estados poscoloniales que emergieron en la segunda mitad del siglo XX, sin excepción, promulgaron una constitución al lograr su independencia. En los años 70 , además, las constituciones de los países poscoloniales conformaban $2 / 3$ de las constituciones del mundo y en los años 90 , incluyendo ya a los nuevos Estados de Europa del Este, se podían contar 415 constituciones poscoloniales. En la Guerra Fría los contenidos de las constituciones poscoloniales dependieron de la alineación de los estados que regulaban con una u otra potencia. Luego de la caída de la Unión Soviética esta dualidad se debilitó radicalmente y los contenidos de las constituciones poscoloniales han tendido a favorecer los principios e instituciones liberales. El caso de los países de Europa Oriental es, tal vez, el más evidente. Sin embargo, este es también el caso en países africanos como Cabo Verde y asiáticos, como las Islas Maldivas. Julian Go, supra nota 10, págs. 83-90. Los contenidos de las constituciones postcoloniales también varían dependiendo de la posición que se ocupe en el eje religioso, aunque este eje se entrecruce con el ideológico. En América Latina, durante la primera ola de descolonización, países como Colombia, Argentina y Chile reconocieron al catolicismo como la religión oficial. En África y medio oriente, durante la tercera ola de descolonización, constituciones como las de Mauritania, Comoras y Somalia reconocieron una religión oficial, típicamente el islam. En Asía, algunas constituciones como la de Camboya, Laos y Burma reconocieron al budismo como religión oficial. Julian Go, supra nota 10, pág. 78.

68 Luis Eslava, The Developmental State: Independence, Dependency, and History of the South, en Philipp Dann \& Jochen v. Bernstorff, eds., The Battle for International Law in the Decolonization Era 71-100 (Oxford University Press, 2019).

69 Michael Riegner, Comparative Foreign Relations Law between Centre and Periphery. Liberal and Postcolonial Perspectives, en Helmut Aust y Thomas Kleinlein, eds., Encounters Between Foreign Relations Law And Public International Law. Bridges And Boundaries 60-85 (Cambridge University Press, 2020).

70 David Trubek \& Marc Galanter, Scholars in Self-Estrangement: Some Reflections on the Crisis in Law and Development Studies in the United States, 4 Wisconsin Law Review 1062-1102 (1974).

71 Dane Kennedy, supra nota 1, págs. 74-76.

72 Véase, por ejemplo, la Constitución de Lituania de 1992 (modificada en 2019). Su preámbulo dice lo siguiente: "LA NACIÓN LITUANA, habiendo creado el Estado de Lituania hace muchos siglos, habiendo basado sus fundamentos legales en los Estatutos lituanos y las Constituciones de la República de Lituania, habiendo defendido firmemente durante siglos su libertad e independencia, habiendo conservado su espíritu, lengua nativa, escritura y costumbres, habiendo incorporando en el Estado independiente de Lituania el derecho innato del ser humano y de la Nación a vivir y crear libremente en la tierra de sus padres y antepasados, fomentando la concordia nacional en la tierra de Lituania, 
luchando por una sociedad civil abierta, justa y armoniosa y un Estado bajo el imperio de la ley, por la voluntad de los ciudadanos del renacido Estado de Lituania, adopta y proclama esta Constitución "; véanse también el preámbulo de la Constitución Argentina de 1853 (reinst. 1983, rev. 1994), que establece, "Nos los representantes del pueblo de la Nación Argentina, reunidos en Congreso General Constituyente por voluntad y elección de las provincias que la componen, en cumplimiento de pactos preexistentes, con el objeto de constituir la unión nacional, afianzar la justicia, consolidar la paz interior, proveer a la defensa común, promover el bienestar general, y asegurar los beneficios de la libertad, para nosotros, para nuestra posteridad, y para todos los hombres del mundo que quieran habitar en el suelo argentino: invocando la protección de Dios, fuente de toda razón y justicia: ordenamos, decretamos y establecemos esta Constitución para la Nación Argentina; Véanse también los artículos 1 y 2 de la Constitución colombiana de 1886: "Artículo $1^{\circ}$. La Nación Colombiana se reconstituye en forma de República unitaria". "Artículo $2^{\circ}$. La soberanía reside esencial y exclusivamente en la Nación, y de ella emanan los poderes públicos"; y la introducción a la Constitución haitiana de 1811: "[Considerando] que es la nación la que ahora ejerce, a través de nosotros, su voluntad y su soberanía, al confiarlas a quien la ha rescatado de ese abismo en el que sus enemigos más empedernidos la extinguirían, a quien la gobierna con tanta gloria, esta nación no tiene nada que temer por su libertad, su independencia y su felicidad". Finalmente, véanse el preámbulo de la Constitución de Camboya de 1993, "NOSOTROS, EL PUEBLO DE CAMBOYA Siendo los herederos de una gran civilización, una nación próspera, poderosa, grande y gloriosa cuyo prestigio irradiaba como un diamante; habiendo soportado el sufrimiento y la destrucción y habiendo experimentado un trágico declive en el transcurso de las últimas dos décadas; Habiendo despertado para levantarnos con firme determinación y compromiso para fortalecer nuestra unidad nacional, para preservar y defender el territorio de Camboya y su preciosa soberanía y el prestigio de la civilización de Angkor, para construir la nación de manera que vuelva a ser una "Isla de Paz" basada en un sistema democrático liberal multipartidista, para garantizar los derechos humanos y el respeto de la ley, y ser responsable de desarrollar progresivamente la prosperidad y gloria de nuestra nación...”; la Constitución de Camerún de 1972: "PREÁMBULO Nosotros, el pueblo de Camerún, Orgullosos de nuestra diversidad lingüística y cultural, rasgo que enriquece nuestra identidad nacional, pero profundamente conscientes de la imperiosa necesidad de consolidar aún más nuestra unidad, declaramos solemnemente que constituimos una y la misma Nación, unidos por un mismo destino, y afirmamos nuestra firme determinación de construir la Patria de Camerún sobre la base de los ideales de fraternidad, justicia y progreso"; y Benedict Anderson, Imagined Communities. Reflections on the Origin and Spread of Nationalism (Verso, 2006).

73 "Nosotros, el Pueblo de la República Federal de Nigeria, HABIENDO decidido de manera firme y solemne VIVIR en unidad y armonía como una nación soberana indivisible ante Dios, dedicada a la promoción de la solidaridad interafricana, la paz mundial y la cooperación y el entendimiento internacionales"; y Sylvester Ogoh Alubo, Ethnic Conflicts and Citizenship Crises in the Central Region, Programme on Ethnic and Federal Studies (2006).

74 Véanse, por ejemplo, la Constitución india de 1949, "Artículo 51A. DEBERES FUNDAMENTALES Será deber de todo ciudadano de la India - acatar la Constitución y respetar sus ideales e instituciones, la Bandera Nacional y el Himno Nacional; b. apreciar y seguir los nobles ideales que inspiraron nuestra lucha nacional por la libertad; c. defender el país y prestar servicio nacional cuando se le solicite; luchar por la excelencia en todas las esferas de la actividad individual y colectiva para que la nación se eleve constantemente a niveles más altos de esfuerzo y logro"; "Artículo 38. EL ESTADO HA DE GARANTIZAR UN ORDEN SOCIAL PARA LA PROMOCIÓN DEL BIENESTAR DEL PUEBLO 1. El Estado se esforzará por promover el bienestar del pueblo asegurando y protegiendo con la mayor eficacia posible un orden social en el que la justicia social, económica y política, debe dar forma a todas las instituciones de la vida nacional”; y “Artículo 49 PROTECCIÓN DE MONUMENTOS Y LUGARES Y OBJETOS DE IMPORTANCIA NACIONAL Será obligación del Estado proteger todo monumento o lugar u objeto de interés artístico o histórico, declarado por o bajo ley emitida por el Parlamento como de importancia nacional, del expolio, desfiguración, destrucción, remoción, disposición o exportación, según sea el caso"; véase, también, Gurpreet Mahajan, Indian Exceptionalism or Indian Model: Negotiating Cultural Diversity and Minority Rights in a Democratic NationState, en Multiculturalism in Asia, 288-313, Baogang He y Will Kymlicka, Eds., Oxford University Press, 2005).

75 Upendra Baxi, supra nota 2.

76 Véanse, por ejemplo, el art. 1 de la Constitución boliviana de 2009: “Bolivia se constituye en un Estado Unitario Social de Derecho Plurinacional Comunitario, libre, independiente, soberano, democrático, intercultural, descentralizado y con autonomías. Bolivia se funda en la pluralidad y el pluralismo político, económico, jurídico, cultural y lingüístico, dentro del proceso integrador del país"; Mostafa Rejai \& Cynthia H. Enloe, Nation-States and State-Nations, 13 International Studies Quarterly 140-158 (1969); y Boaventura de Sousa Santos, Refundación del estado en América Latina. Perspectivas desde una epistemología del sur (Siglo del Hombre Editores, 2010).

77 Philipp Dann \& Arun Thiruvengadam (eds.), Democratic Constitutionalism in Continental Polities: Eu And India Compared (Edward Elgar, 2021); Antonio Carlos Wolkmer \& Ivone Fernandes Morcilo Lixa, supra nota 48; Francis Mading Deng, Identity, Diversity, and Constitutionalism in Africa (United States Institute of Peace (2008). El caso español resulta particularmente ilustrativo de los retos que implica la reconstrucción de una identidad colectiva 
postimperial. Veánse, por ejemplo, María Elvira Roca, Imperofobia y leyenda negra (Siruela, 2016) y José Luis Villacañas, Imperiofilia y el populismo nacional católico (Lengua de Trapo, 2019).

78 Donald Bruce Marshall, The French Colonial Myth And Constitution-Making In The Fourth Republic, Yale University Press, New Haven (1973); Dane Kennedy, supra nota 1, págs. 56, 79-80.

79 Dane Kennedy, Id., pág. 62.

80 Ruth Craggs \& Harshan Kumarasingham, Losing an Empire and Building a Role: The Queen, Geopolitics and the Construction of the Commonwealth Headship at the Lusaka Commonwealth Heads of Government Meeting, 1979, 43 The Journal of Imperial and Commonwealth History 5, 80-98 (2015); Harshan Kumarasingham, Written Differently: A Survey of Commonwealth Constitutional History in the Age of Decolonisation, 46 The Journal of Imperial and Commonwealth History 5, 874-908 (2018).

81 Dane Kennedy, supra nota 1, págs. 38, 94.

82 Morten Broberg, The EU's Legal Ties with its Former Colonies: When Old Love Never Dies 4-18, en Working Paper, n. 2011:01 (Danish Institute for International Studies, 2011).

83 James Tully, Modern Constitutional Democracy and Imperialism, 46, 3 Osgoode Hall Law Journal, 461-493, 471-472 (2008).

84 Allison Stone, Hegel and Colonialism, 41 Hegel Bulletin 2, 1-24 (2017).

85 Camilla Boisen, The Changing Moral Justification of Empire: From the Right to Colonise to the Obligation to Civilise, 39 History of European Ideas 335-353, 345 (2013).

86 Sobre el caso de Gran Bretaña véase, por ejemplo, K. Kumar, Nation and Empire: English and British National Identity in Comparative Perspective, 29 Theory and Society 5, 575-608 (2000).

87 Véase, por ejemplo, María Elvira Roca, Imperofobiay leyenda negra (Siruela, 2016) y José Luis Villacañas, Imperiofiliay el populismo nacional católico (Lengua de Trapo, 2019).

88 Véase, por ejemplo, la disputa legal sobre los presuntos abusos y torturas por parte de funcionarios británicos durante la insurgencia Mau Mau. Royal Courts of Justice. Ndiku Mutua and Others and the Foreign and Commonwealth Office: The Hon Mr Justice McCombe, Summary of Judgment. Case n. ${ }^{\circ}$ HQ09X02666: London: Royal Courts of Justice, 2011; véanse, también, Alfred W. B. Simpson, Human Rights and the end of Empire. Britain and the Genesis of the European Convention 924 (Oxford University Press, 2010); Judith Hackmack, Colonial repercussions in Germany and Namibia (Völkerrechtsblog, 2019); David M. Anderson, Mau Mau in the High Court and the 'Lost' British Empire Archives: Colonial Conspiracy or Bureaucratic Bungle?, 39 Journal of Imperial and Commonwealth History 5, 699-716 (2011).

89 Véase, por ejemplo, la discusión sobre la Casa de la Historia Europea y algunas de sus publicaciones. Committee of Experts. 2008. Conceptual Basis for a House of European History, http://www.europarl.europa.eu/ meetdocs/2004_2009/documents/dv/745/745721/745721_en.pdf.; véase, también, Britta Schilling, Postcolonial Germany. Memories of Empire in a Decolonized Nation (Oxford University Press, 2014).

90 Ley n. 2005-158 del 23 de febrero de 2005, sobre el reconocimiento de la Nación y la contribución nacional a favor de los repatriados franceses: "Artículo 4 (Modificado por el Decreto n. ${ }^{\circ}$ 2006-160 de 15 de febrero de 2006 - art. 1 JORF, 16 de febrero, 2006). Los programas de investigación universitarios darán a la historia de la presencia de Francia en el extranjero, particularmente en el norte de África, el lugar que se merece”. Véase, también, Uladzislau Belavusau \& Aleksandra Gliszczyńska-Grabias, Introduction: Memory Laws: Mapping a new Subject in Comparative Law and Transitional Justice, en Uladzislau Belavusau \& Aleksandra Gliszczyńska-Grabias, eds., Law And Memory. Towards Legal Governance Of History 1 (Cambridge University Press, 2017).

91 Véase, por ejemplo, John W.P. Veugelers, Empire's Legacy: Roots of a Far-Right Affinity in Contemporary France (Oxford University Press, 2020).

92 Linda Bishai, Liberal Empire, 7 Journal of International Relations and Development 48-72 (2004).

\section{Licencia Creative Commons CC BY 4.0}

Cómo citar este artículo: Michael Riegner \& Daniel Bonilla Maldonado, Historia, Estado y nación. El constitucionalismo y los procesos de descolonización, 70 Vniversitas (2021), https://doi.org/10.11144/Javeria na.vj70.henc 